\title{
The Identification of Gas-liquid Co-current Two Phase Flow Pattern in a Horizontal Pipe Using the Power Spectral Density and the Artificial Neural Network (ANN)
}

\author{
Budi Santoso $^{1,4}$ Indarto $^{2}$, Deendarlianto ${ }^{2} \&$ Thomas S. W. ${ }^{3}$ \\ ${ }^{1}$ Graduate Program of Mechanical and Industrial Engineering, Faculty of Engineering, GadjahMada University, \\ Indonesia \\ ${ }^{2}$ Department of Mechanical and Industrial Engineering, Faculty of Engineering, GadjahMada University, \\ Indonesia \\ 3 Departmen of Electrical Engineering and Information Technology, Faculty of Engineering, GadjahMada \\ University, Indonesia \\ ${ }^{4}$ Department of Mechanical Engineering, Faculty of Engineering, SebelasMaret University, Indonesia \\ Correspondence: Budi Santoso, Department of Mechanical Engineering, Faculty of Engineering, SebelasMaret \\ University, Jl. Sutarmi 36A Surakarta 57126, Indonesia. E-mail: msbudis@yahoo.co.id; budisant@mail.uns.ac.id
}

Received: July 23, $2012 \quad$ Accepted: August 18, $2012 \quad$ Online Published: August 29, 2012

doi:10.5539/mas.v6n9p56 URL: http://dx.doi.org/10.5539/mas.v6n9p56

\begin{abstract}
This paper presents a new method of the flow pattern identification on the basis of the analysis of Power Spectral Density (PSD) from the pressure difference data of horizontal flow. Seven parameters of PSD curve such as mean (K1), variance (K2), mean at $1-3 \mathrm{~Hz}(\mathrm{~K} 3)$, mean at 3-8 Hz (K4), mean at 8-13 Hz (K5), mean at 13-25 Hz (K6) and mean at $25-30 \mathrm{~Hz}(\mathrm{~K} 7)$ were used as training vector input of Artificial Neural Networks (ANN) in order to identify the flow patterns. From the obtained experimental of 123 operating conditions consisting of stratified flow, plug and slug, ANN was trained by using 100 data operation and 23 tested data. The results showed that the new method has a capability to identify the flow patterns of gas-liquid two phase flow with a high accuracy.
\end{abstract}

Keywords: flow pattern identification, power spectral density (PSD), artificial neural network (ANN), two phase flow

\section{Introduction}

The knowledge of two phase flow is of important in engineering process, such as oil industry, chemical process, power generation, and phase change heat exchanger apparatus. The common characteristics of parameter related to the flow pattern are the pressure gradient and the void fraction. The main issue in two phase flow researches is the relationship between the pressure fluctuation and flow pattern. In general, the pressure fluctuations resulted from the liquid-gas flow and their statistical characteristics are very interest for the objective characterization of the flow patterns because the required sensors are robust, inexpensive and relatively well established, and therefore more likely to be implemented in the industrial systems (Drahos et al., 1991).

Drahos et al. (1996) has already conducted the study of the wall pressure fluctuations in a horizontal gas-liquid flow by using the methodology of chaotic time series analysis in order to obtain a new insight of the dynamics of the intermittent flow patterns. Next, Franca et al. (1991) presented the fractal techniques for flow pattern identification and classification. They observed that PSD and PDF could not easily be used for the flow pattern identification and the objective discrimination between separated and intermittent regimes. Ding et al. (2007) reported the application of the Hilbert-Huang Transform (HHT) to the dynamic characterization of transportation of the gas-liquid two-phase flow in a horizontal pipe. Matsui et al. (2007) studied the sensing method of gas-liquid two phase flow in horizontal pipe on the basis of statistical processing of differential pressure fluctuation. The flow pattern, the void fraction and the velocity of gas phase were measured by PDF and cross correlation. From the view point of engineering, the above method's are subjective in nature, therefore a newly scientific based method is needed. 
Artificial Neural Network (ANN) provides an alternative method for either modeling phenomena which are too difficult to model from fundamental principles, or reduce the computational time for predicting expected behavior. Artificial neural network is based on the important rules for classifying the flow pattern. Neural network stimulate human mind and demonstrate high intelligence and it can be trained to study the correct output and classify training exercises. Here, neural network needs knowledge input for training. After the training, the neural network can classify the similar flow pattern with a high accuracy.

Cai et al. (1994) applied the Kohonen self-organizing neural network in order to identify the flow pattern in a horizontal air-water flow. In their work, the neural network was trained with stochastic features derived from the turbulent absolute pressure signals obtained across a range of the flow regimes. The feature map succeeded in classifying samples into distinctive flow regime classes consistent with the visual flow regime observation. Next, $\mathrm{Wu}$ et al. (2001) recorded the pressure difference signal in pipe flow and used the fractal analysis to analyze them for identification of flow pattern. By using the ANN, the good result was obtained but it is only considered stratified, intermittent and annular flows. For this reason, Jia et al. (2005) proposed a new flow pattern identification method based on PDF and neural network at the horizontal flow in pipe.

Xie et al. (2004) examined the feasibility of the implementation of the artificial neural network (ANN) technique for the classification of flow regimes in three phase gas/liquid/pulp fiber systems by using the pressure signals as input. For this purpose, the flow behavior by using the power spectral density function is needed to implement the parameterization of the information contained in the spectral patterns.

Table1. The experiment conditions using pressure sensor

\begin{tabular}{|c|c|c|c|c|}
\hline Authors & System & $\begin{array}{l}\text { Diameter/ } \\
\text { Orientation } \\
\end{array}$ & Measurement technique & Method and finding \\
\hline $\begin{array}{l}\text { Franca et al. } \\
\text { (1991) }\end{array}$ & $\begin{array}{l}\text { Water-air (wavy, } \\
\text { plug, slug and } \\
\text { annular) }\end{array}$ & $\begin{array}{l}\mathrm{D}=19 \mathrm{~mm} \text {; } \\
\text { horizontal }\end{array}$ & $\begin{array}{l}\text { Pressure drop, } X_{\mathrm{DP}}=8 \mathrm{D}, \\
\mathrm{N}=5000\end{array}$ & $\begin{array}{l}\text { Using fractal techniques for } \\
\text { flow pattern identification } \\
\text { and classification. }\end{array}$ \\
\hline $\begin{array}{l}\text { Cai et al. } \\
\text { (1994) }\end{array}$ & $\begin{array}{l}\text { Water-air } \\
\text { (stratified, slug, } \\
\text { intermittent } \\
\text { transition, and } \\
\text { bubble) }\end{array}$ & $\begin{array}{l}\mathrm{D}=50 \mathrm{~mm} \\
\text { horizontal }\end{array}$ & $\begin{array}{l}\text { Two absolute pressure, } \\
\mathrm{X}_{\mathrm{DP}}=1 \mathrm{D}, \mathrm{SR}=40 \mathrm{~Hz} \\
\mathrm{~N}=40000\end{array}$ & $\begin{array}{l}\text { Kohonen self-organizing } \\
\text { neural network to identify } \\
\text { flow regimes. }\end{array}$ \\
\hline $\begin{array}{l}\text { Drahos et al. } \\
\text { (1996) }\end{array}$ & $\begin{array}{l}\text { Water-air (plug } \\
\text { and slug) }\end{array}$ & $\begin{array}{l}\mathrm{D}=50 \mathrm{~mm} \text {; } \\
\text { horizontal }\end{array}$ & $\begin{array}{l}\text { wall pressure } \\
\text { fluctuations, } X_{D P}=8 D, \\
S R=500 H z, N=60000\end{array}$ & $\begin{array}{l}\text { Chaotic time series analysis } \\
\text { to obtain a new insight into } \\
\text { the dynamics of the } \\
\text { intermittent flow pattern. }\end{array}$ \\
\hline $\begin{array}{l}\text { Wu et al. } \\
(2001)\end{array}$ & $\begin{array}{l}\text { Oil-gas-water, } \\
\text { (stratified, } \\
\text { intermittent and } \\
\text { annular) }\end{array}$ & $\begin{array}{l}\mathrm{D}=40 \mathrm{~mm} \\
\text { horizontal }\end{array}$ & $\begin{array}{l}\text { Differential pressure, } \\
X_{D P}=5 \mathrm{D}\end{array}$ & $\begin{array}{l}\text { The fractal analysis to } \\
\text { analyze the signal for } \\
\text { identification of flow } \\
\text { pattern. }\end{array}$ \\
\hline $\begin{array}{l}\text { Jia et al. } \\
\text { (2005) }\end{array}$ & $\begin{array}{l}\text { Water-air } \\
\text { (stratified, churn, } \\
\text { slug, annular) }\end{array}$ & $\begin{array}{l}\mathrm{D}=32 \mathrm{~mm} \\
\text { horizontal }\end{array}$ & $\begin{array}{l}\text { Differential pressure, } \\
\mathrm{X}_{\mathrm{DP}}=10 \mathrm{D}, \mathrm{SR}=200 \mathrm{~Hz}, \\
\mathrm{~N}=6000\end{array}$ & $\begin{array}{l}\text { Flow pattern identification } \\
\text { method based on PDF and } \\
\text { neural network. }\end{array}$ \\
\hline $\begin{array}{l}\text { Matsui et al. } \\
\text { (2007) }\end{array}$ & $\begin{array}{l}\text { Water and } \\
\text { nitrogen gas } \\
\text { (small bubble } \\
\text { train, plug and } \\
\text { slug) }\end{array}$ & $\begin{array}{l}\mathrm{D}=7 \mathrm{~mm} \text {; } \\
\text { horizontal }\end{array}$ & $\begin{array}{l}\text { Differential pressure, } \\
X_{D P}=1 D, \quad X_{D P}=7 D \\
S R=100 \mathrm{~Hz}, N=2000\end{array}$ & $\begin{array}{l}\text { The flow pattern, the void } \\
\text { fraction and the velocity of } \\
\text { gas phase were measured by } \\
\text { PDF and cross correlation. }\end{array}$ \\
\hline $\begin{array}{l}\text { Hao et al. } \\
(2007)\end{array}$ & $\begin{array}{l}\text { Water-air, (wavy, } \\
\text { bubble, plug and } \\
\text { slug) }\end{array}$ & $\begin{array}{l}\mathrm{D}=15 \mathrm{~mm}, 25 \\
\mathrm{~mm}, 40 \mathrm{~mm} \text {; } \\
\text { horizontal }\end{array}$ & $\begin{array}{l}\text { Differential pressure, } \\
X_{D P}=250 \mathrm{~mm}, \\
S R=200 \mathrm{~Hz}, N=30000\end{array}$ & $\begin{array}{l}\text { The application of the } \\
\text { Hilbert-Huang Transform } \\
\text { (HHT) to identify flow } \\
\text { regimes. }\end{array}$ \\
\hline $\begin{array}{l}\text { Xie et al. } \\
(2004)\end{array}$ & $\begin{array}{l}\text { Gas-liquid-pulp } \\
\text { fiber (churn, } \\
\text { slug) }\end{array}$ & $\begin{array}{l}D=50.8 \mathrm{~mm} \\
\text { vertical }\end{array}$ & $\begin{array}{l}\text { Local pressure } \\
\text { fluctuations, } S R=200 \mathrm{~Hz}, \\
\mathrm{~N}=2000\end{array}$ & $\begin{array}{l}\text { To characterize the } \\
\text { hydrodynamics of the flow } \\
\text { based on the power spectral } \\
\text { density function. }\end{array}$ \\
\hline
\end{tabular}


The summary of experiment conditions from the previous researcher is shown in Table 1, where $\mathrm{X}_{\mathrm{DP}}$ is distance of pressure tap (mm), SR is sampling rate and $\mathrm{N}$ is size of data. It gave the information about the method of flow pattern identification, distance of pressure tap, sampling rate, size of data and flow pattern identified. Those studies have contributed to our understanding of flow patterns of two-phase flows and losing the subjective judgment of researchers in flow pattern identification. In this paper, the differential pressure, the analysis of PSD and back propagation neural network was used to identify flow pattern of two phase flow at a horizontal pipe. An ANN was designed, trained and tested for the classification of the flow regimes using as input some density characteristics of the power spectrum for one of the normalized differential pressure signals and was shown to predict the flow regimes with good accuracy.

\section{Experiments Apparatus and Procedure}

Figure 1 shows a schematic diagram of the experimental apparatus used in the present study. Air supplied from a compressor and water from pump into an air-water mixing section after their flow rates are measured individually by flow meters. The air-water mixture flows through the tube into an air-water separator, where air is released into the atmosphere and water is measured more accurately by weighing if necessary. A smooth tube of $24 \mathrm{~mm}$ inner diameter and of $9 \mathrm{~m}$ total length is made of transparent acrylic resin to observe the flow pattern.
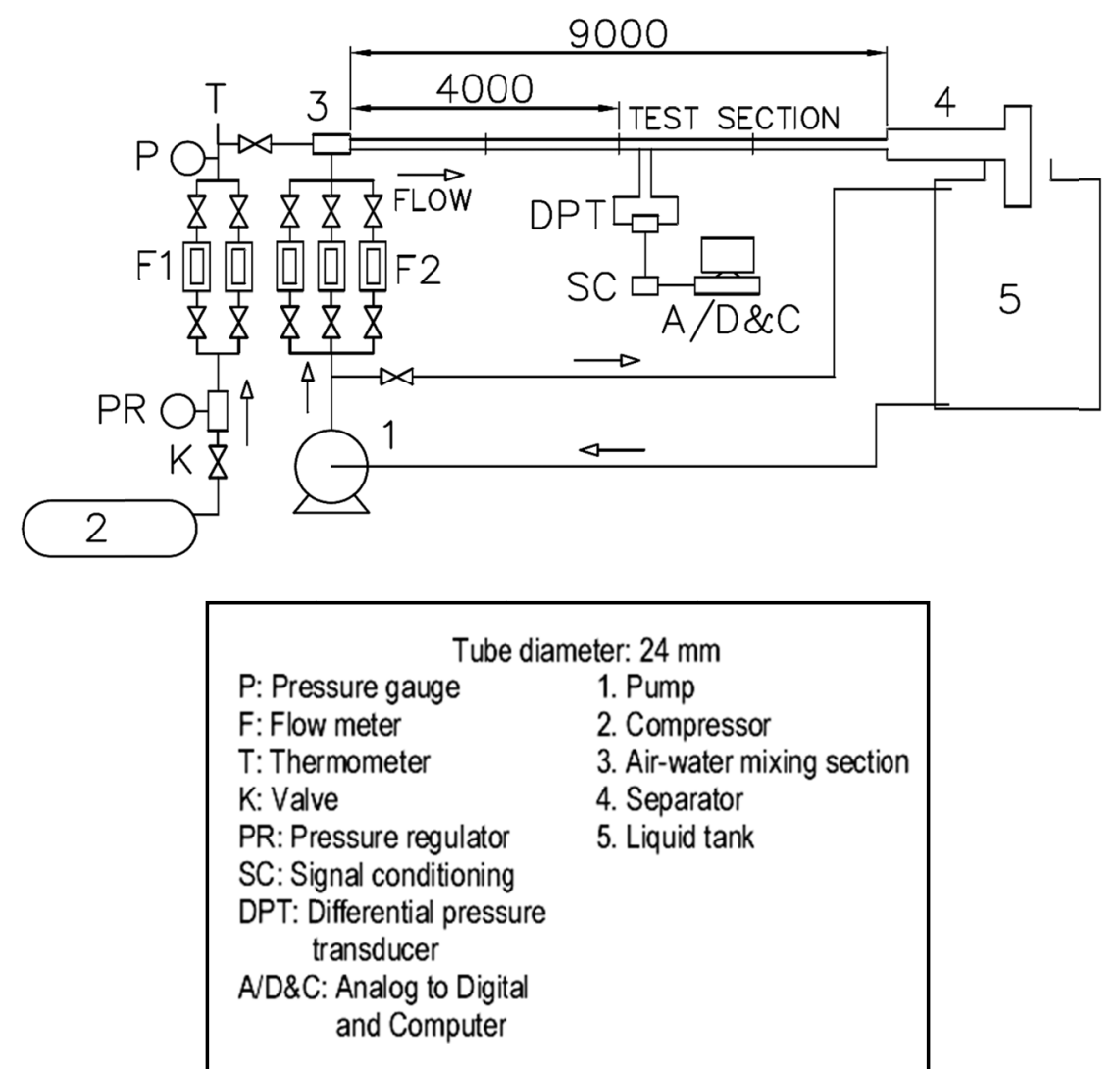

Figure 1. Schematic diagram of the experimental apparatus

As shown in the Figure 1, the pressure fluctuation was detected by Validyne DP15-32 differential pressure transducer with 5D distance of pressure tap. The transducer has $\pm 0.25 \%$ full scale accuracy. Output signals from transducer were sent through amplifier into a computer via A/D converter. Sampling rate was $400 \mathrm{~Hz}$ and the measuring time of experimental run was $50 \mathrm{~s}$. The working fluids were air and water. The experiment conditions are as follows: the range of superficial air and water velocities; $\mathrm{J}_{\mathrm{G}}=0.085-3.204 \mathrm{~m} / \mathrm{s}$, and those $\mathrm{J}_{\mathrm{L}}=0.016-1.255$ $\mathrm{m} / \mathrm{s}$.

\section{Results and Discussions}

\subsection{Flow Patterns}

Figure 2 shows the typical results of the flow patterns obtained from the present experiment. The Figures, (a), (b) and (c) correspond to interfacial behavior of the stratified, plug and slug flows, respectively. In the stratified flow, 
the gas phase travels along the upper half of the tube while the liquid flows along the bottom with no significant interfacial waves. As shown in Figure 2(a), this flow has the simplest configuration of all the horizontal flow patterns. The stratified flow pattern occurs at relatively low gas and liquid mass flow rates and density difference of fluid. As shown in the Figure 2(b) the plug flow is characterized by elongated bubbles flowing along the top of the tube in a continuous liquid flow. Next, it is noticed that in the plug flow; elongated bubbles move at the same velocity with the liquid, and the gas-liquid interface below the bubbles is relatively stable, indicating a small difference between the velocities of the phases at the interface. With the increase gas velocity, the magnitude of the waves increases. This condition is called slug flow. Ultimately, the waves build up and reach the upper wall of the tube to form some liquid packets, also liquid slugs. These liquid slugs are then transported at the higher velocity of the gas (Figure 2(c)). Unlike plug flow, in which the elongated bubbles of gas are transported by the liquid phase, in slug flow the liquid slugs are carried by the faster moving gas flow. The slug flow pattern is highly undesirable in practical applications. The faster moving liquid slugs are usually associated with sudden pressure pulses and severe pressure oscillations that can cause damage to downstream equipment.

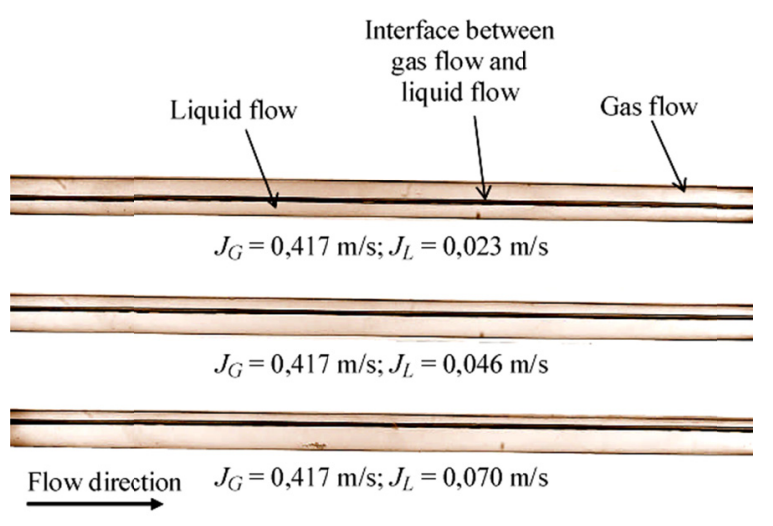

(a) Stratified flow

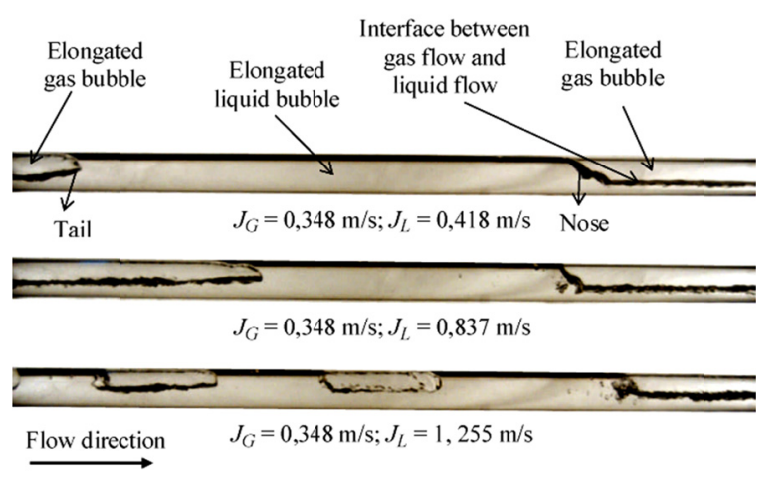

(b) Plug Flow

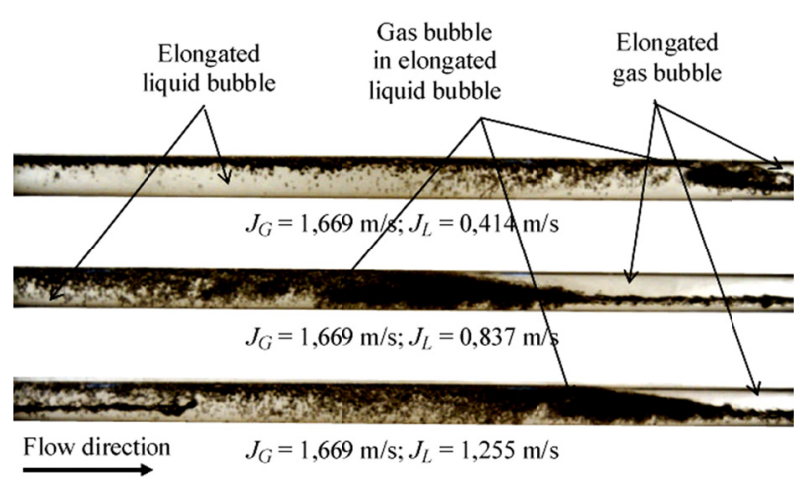

(c) Slug Flow

Figure 2. Typical results of the observed flow patterns

Finally, the obtained flow pattern data is compared with the horizontal flow pattern map proposed by Mandhane et al. (1974) as shown in Figure 3. Close observation of this figure reveal that the obtained flow pattern data are in agreement with those of Mandhane et al. (1974). 


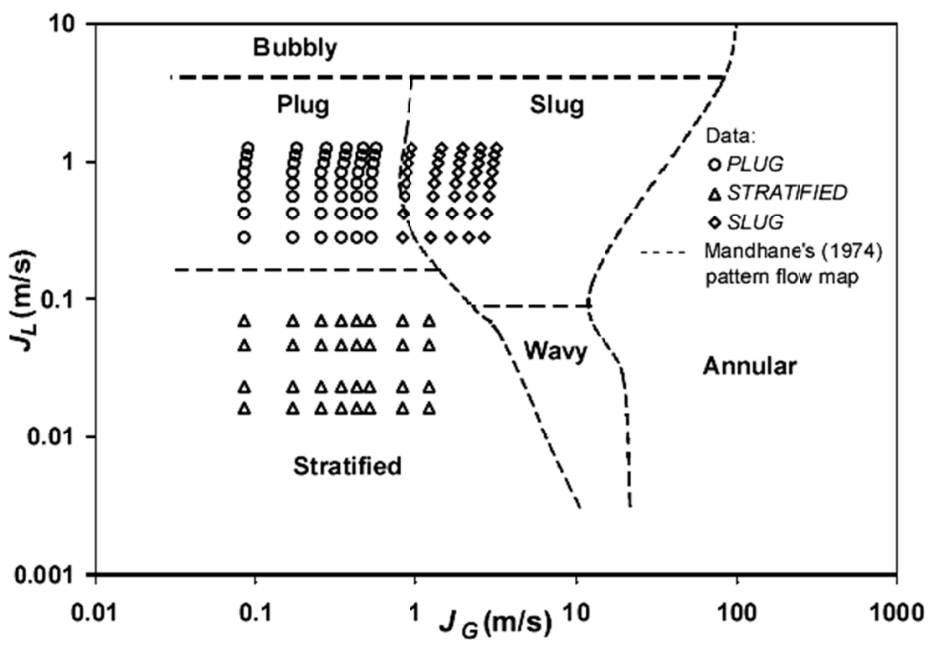

Figure 3. Flow patterns map

Figure 4 shows the structure of the intelligent identification system used in present study. As shown in Figure 4, the system of flow pattern identification is composed of differential pressure measuring unit, data acquisition unit and data processing unit. Differential pressure measuring unit and data acquisition unit constitute the hardware part of the system, while data processing unit constitutes the software part of the system.

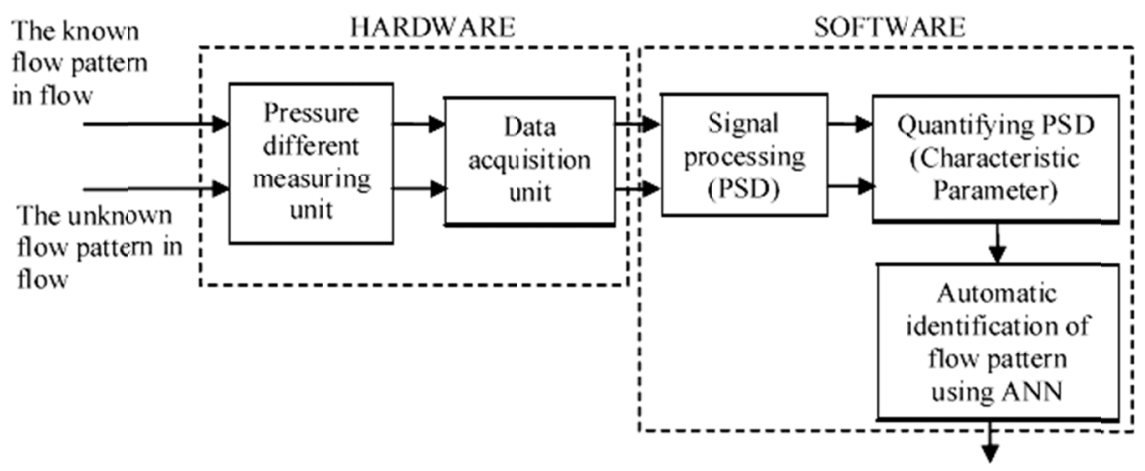

The type of flow pattern

Figure 4. Structure of the intelligent identification system

Here, the normalized pressure fluctuations in the time series is defined below:

$$
D P^{*}=(D P-\overline{D P}) / \sqrt{\overline{(D P-\overline{D P})^{2}}}
$$

Where $D P$ is differential pressure $(\mathrm{Pa}), \overline{D P}$ is average differential pressure $(\mathrm{Pa})$ and $D P^{*}$ is normalized pressure different signal $(\mathrm{Pa})$. The power spectrum was estimated using the segments with a length of 16834 points and a Hanning Window of the same size.

\subsection{Typical Flow pattern and Power Spectral Density}

In this paper, three typical flow patterns ware identified. The characteristics of their PSD were used to identify the different of the flow patterns. Examples of time series pressure different and power spectra for the major flow patterns are shown in Figure 5 to Figure 7.

\subsubsection{Stratified Flow}

Time series signal and PSD of stratified flow is shown at Figure 5, in which it shows a low mean pressure difference with a small fluctuation. This flow pattern occurs at low superficial velocities of water and air and the interface between water flow and air flow is clear (no bubble). From Figure 5(b), it is revealed that the stratified flow has one peak and spreads over wide frequency range from 8 to $27 \mathrm{~Hz}$. 


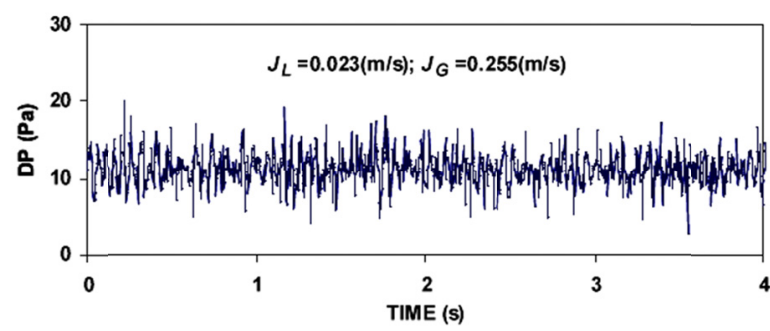

(a) Time series signal

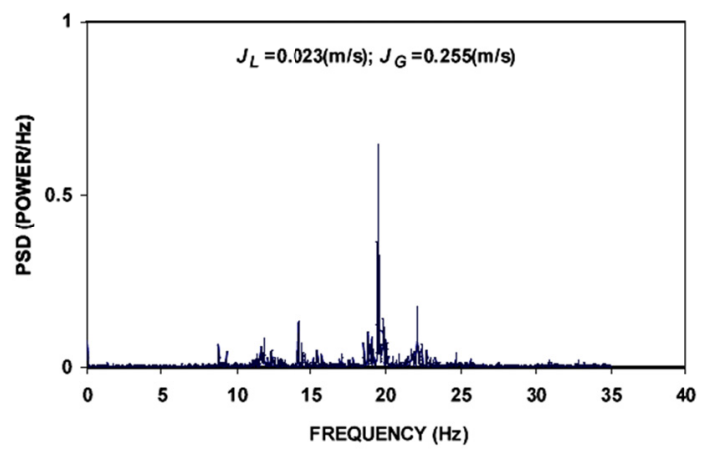

(b) Power spectral density

Figure 5. Typical of the time variation of pressure gradient and the PSD in stratified flow at $\mathrm{J}_{\mathrm{L}}=0.023 \mathrm{~m} / \mathrm{s}$ and

$$
\mathrm{J}_{\mathrm{G}}=0.255 \mathrm{~m} / \mathrm{s}
$$

\subsubsection{Plug Flow}

Figure 6 shows the time variation of pressure gradient and the PSD of plug flow. The time variation the pressure difference of plug flow has a bigger fluctuation than that of stratified flow as shown in Figure 6(a). It is possible due to the air bubble has a compressible effect that cause large fluctuations. The spread values of PSD are divided into two parts. There are in the range of 0-11 Hz and 11-27 Hz (see Figure 6(b)).

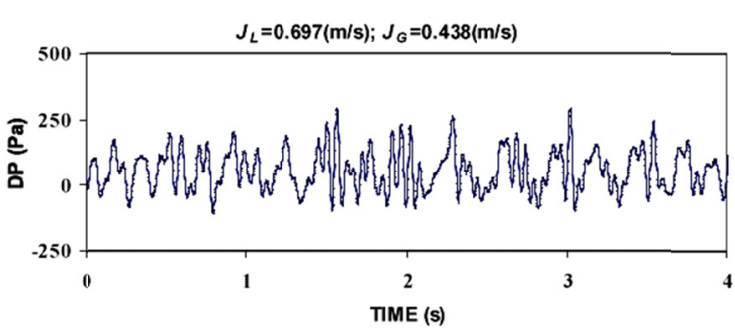

(a) Time series signal

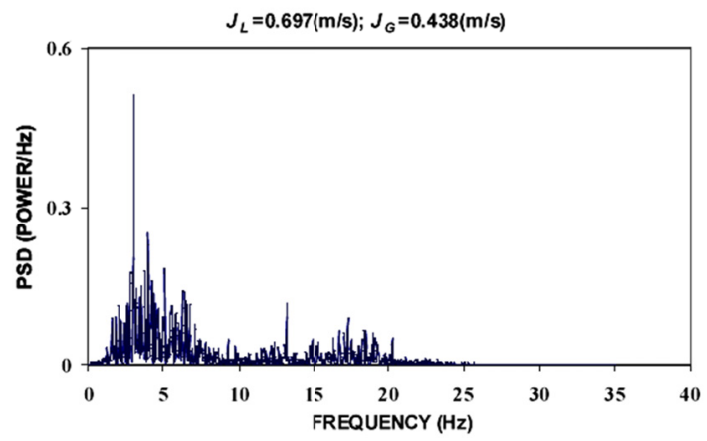

(b) Power spectral density

Figure 6. Typical of the time variation of pressure gradient and the PSD in plug flow at $\mathrm{J}_{\mathrm{L}}=0.697 \mathrm{~m} / \mathrm{s}$ and

$$
\mathrm{J}_{\mathrm{G}}=0.438 \mathrm{~m} / \mathrm{s}
$$

\subsubsection{Slug Flow}

Figure 7 shows the time series signal and the PSD slug flow. Slug flow time series signal has a different pattern when compared with the stratified flow and plug flow, as shown in Figure 7(a). Slug flow time series signal have peaks value that it is caused by the high water velocity pushing the elongated bubbles. Among the top value range present the bubbles flow with zero value. PSD of slug flow has the frequency range in 2-35 Hz with spread of peak value decreases (see Figure 7(b)). 


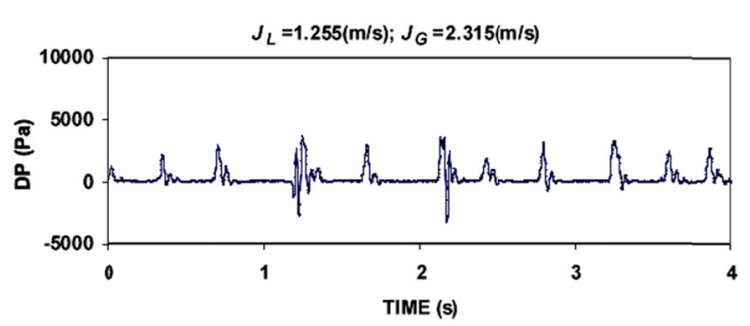

(a) Time series signal

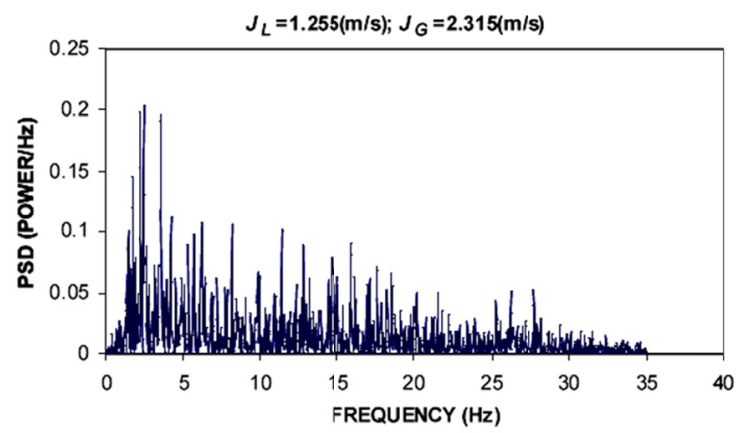

(b) Power spectral density

Figure 7. Typical of time series signal pressure gradient and PSD in slug flow at $\mathrm{J}_{\mathrm{L}}=1.255 \mathrm{~m} / \mathrm{s}$ and $\mathrm{J}_{\mathrm{G}}=2.315 \mathrm{~m} / \mathrm{s}$

\subsection{Flow Pattern Identification Using Back Propagation Neural Networks}

\subsubsection{Characteristic Parameters of PSD}

Based on the recorded power spectra, this works focus on a frequency range up to $30 \mathrm{~Hz}$. The frequency range over $0-30 \mathrm{~Hz}$ is then divided into five bandwidths: 0-3, 3-8, 8-13, 13-25, and 25-30 Hz as performed by Xie (2005). The mean value of power in each of the aforementioned bands, denoted as mean 0-30 (K1), variance 0-30 (K2), mean 0-3 Hz (K3), mean 3-8 Hz (K4), mean 8-13 Hz (K5), mean 13-25 Hz (K6), and mean 25-30 Hz (K7) use as input of neural network training.

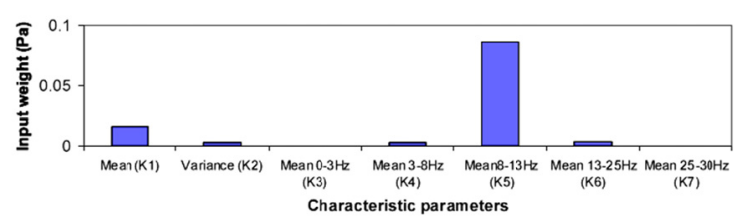

(a) Stratified flow at $\mathrm{J}_{\mathrm{L}}=0.023 \mathrm{~m} / \mathrm{s}$ and $\mathrm{J}_{\mathrm{G}}=0.255 \mathrm{~m} / \mathrm{s}$

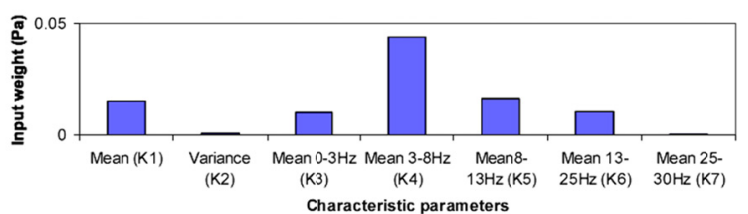

(b) Plug flow at $\mathrm{J}_{\mathrm{L}}=0.697 \mathrm{~m} / \mathrm{s}$ and $\mathrm{J}_{\mathrm{G}}=0.438 \mathrm{~m} / \mathrm{s}$

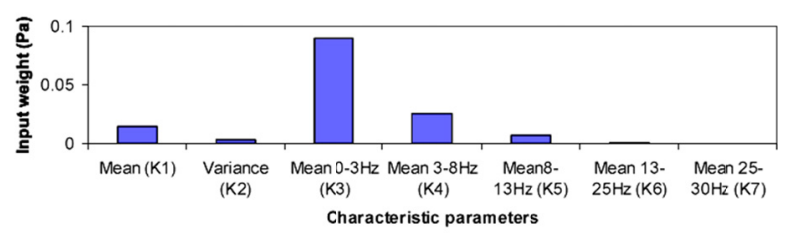

(c) Slug flow at $\mathrm{J}_{\mathrm{L}}=1.255 \mathrm{~m} / \mathrm{s}$ and $\mathrm{J}_{\mathrm{G}}=2.315 \mathrm{~m} / \mathrm{s}$

Figure 8. Characteristic parameters of a PSD 


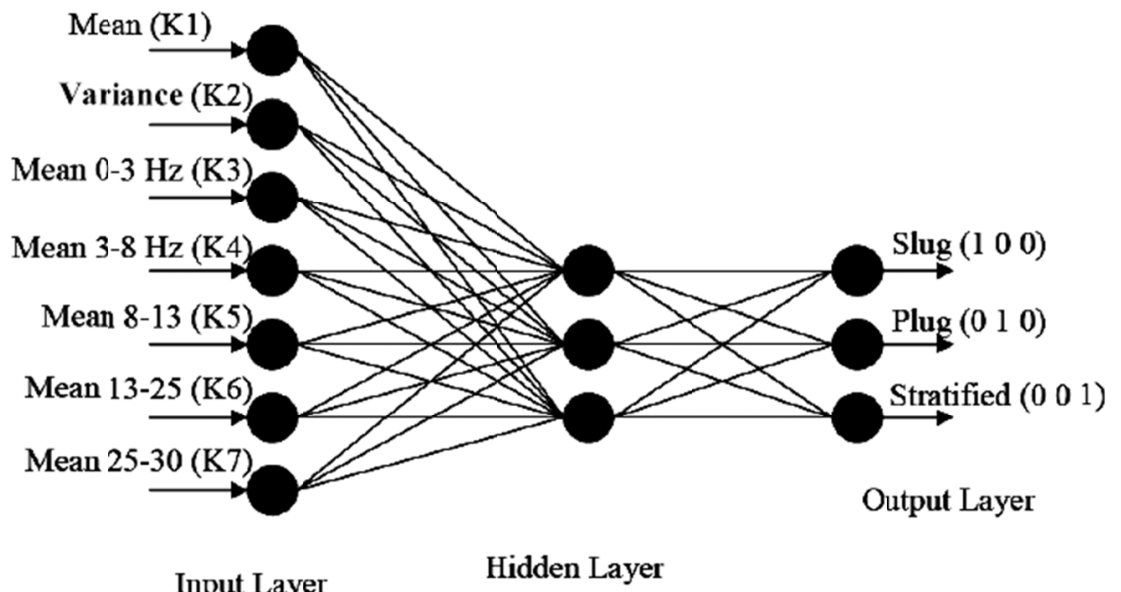

Figure 9. Back propagation neural network architecture is used in this research

Table 2 shows part of characteristic parameters with seven parameter characteristics of PSD for difference operating condition. Those parameters and the output of the flow patterns (stratified flow, plug flow and slug flow) were used to train the back propagation ANN.

Table 2. Examples of the vector characteristic obtained from the present study

\begin{tabular}{|c|c|c|c|c|c|c|c|c|c|c|}
\hline No. Run & $J_{L}(\mathrm{~m} / \mathrm{s})$ & $J_{G}(\mathrm{~m} / \mathrm{s})$ & K1 & K2 & K3 & K4 & K5 & K6 & K7 & $\begin{array}{c}\text { Flow } \\
\text { patterns }\end{array}$ \\
\hline 1 & 0.02 & 0.08 & 0.0083 & 0.0005 & 0.0023 & 0.0016 & 0.0069 & 0.0159 & 0.0029 & Stratified \\
\hline 2 & 0.70 & 0.52 & 0.0159 & 0.0014 & 0.0648 & 0.0434 & 0.0106 & 0.0023 & 0.0002 & Plug \\
\hline 3 & 0.14 & 0.08 & 0.0143 & 0.0039 & 0.1327 & 0.0044 & 0.0012 & 0.0012 & 0.0003 & Plug \\
\hline 4 & 0.28 & 0.82 & 0.0159 & 0.0193 & 0.1408 & 0.0088 & 0.0048 & 0.0002 & 0.0001 & Slug \\
\hline 5 & 0.02 & 0.17 & 0.0084 & 0.0004 & 0.0023 & 0.0017 & 0.0071 & 0.0159 & 0.0033 & Stratified \\
\hline \multicolumn{11}{|l|}{. } \\
\hline \multicolumn{11}{|l|}{. } \\
\hline 96 & 0.05 & 0.51 & 0.0110 & 0.0012 & 0.0130 & 0.0011 & 0.0063 & 0.0203 & 0.0038 & Stratified \\
\hline 97 & 1.26 & 0.27 & 0.0148 & 0.0004 & 0.0032 & 0.0262 & 0.0220 & 0.0168 & 0.0013 & Plug \\
\hline 98 & 0.56 & 0.34 & 0.0159 & 0.0019 & 0.0658 & 0.0366 & 0.0083 & 0.0058 & 0.0002 & Plug \\
\hline 99 & 0.84 & 1.34 & 0.0159 & 0.0038 & 0.1095 & 0.0255 & 0.0057 & 0.0006 & 0.0001 & Slug \\
\hline 100 & 0.05 & 0.82 & 0.0125 & 0.0012 & 0.0160 & 0.0017 & 0.0092 & 0.0189 & 0.0098 & Stratified \\
\hline
\end{tabular}

\subsubsection{Identifying Flow Pattern Using ANN}

Neural networks with a single layer have a limitation in pattern recognition. This drawback can be overcome by adding one or more/multiple hidden layers between input and output layers. Back propagation neural network train the network to get a balance the network's ability to recognize patterns that will be used during training. It also get networking capabilities to provide the correct response (with the input pattern is similar patterns used during training (but not equal)). The use of more than one hidden layers have advantages for some cases, but generally it was begun by trying with one hidden layer.

Back propagation neural network architecture used in the present study is shown in Figure 9. It has one input layer and one hidden layer. The input layer consists of seven neural cells, corresponding to the seven components of the input vectors. The hidden layer consists of three neural cells. The output layer consists of three neural cells, and corresponds to the three different flow patterns of water-air two phase flows in horizontal pipe (stratified flow, plug flow and slug flow). In this paper, let the expected output vector of stratified flow be $(0,0,1)$, that of plug flow be $(0,1,0)$, and that of slug flow be $(1,0,0)$. 
Table 3. Part of test examples and identification results

\begin{tabular}{lllllllcc}
\hline K1 & K2 & K3 & K4 & K5 & K6 & K7 & Flow Patterns & $\begin{array}{c}\text { Identification } \\
\text { results of ANN }\end{array}$ \\
\hline 0.0097 & 0.0011 & 0.0030 & 0.0017 & 0.0074 & 0.0191 & 0.0027 & Stratified & Stratified \\
0.0171 & 0.0009 & 0.0163 & 0.0463 & 0.0080 & 0.0172 & 0.0006 & Plug & Plug \\
0.0155 & 0.0034 & 0.1014 & 0.0298 & 0.0048 & 0.0003 & 0.0001 & Slug & Slug \\
0.0087 & 0.0005 & 0.0039 & 0.0018 & 0.0087 & 0.0150 & 0.0041 & Stratified & Stratified \\
0.0159 & 0.0010 & 0.0232 & 0.0504 & 0.0092 & 0.0102 & 0.0003 & Plug & Plug \\
0.0161 & 0.0028 & 0.1083 & 0.0265 & 0.0064 & 0.0006 & 0.0002 & Slug & Plug $^{*}$ \\
0.0133 & 0.0016 & 0.0041 & 0.0009 & 0.0068 & 0.0268 & 0.0068 & Stratified & Stratified $^{\text {Plug }}$ \\
0.0167 & 0.0011 & 0.0295 & 0.0467 & 0.0081 & 0.0130 & 0.0002 & Plug & Plug \\
0.0178 & 0.0063 & 0.1399 & 0.0190 & 0.0059 & 0.0006 & 0.0003 & Slug & Slug \\
\hline
\end{tabular}

One hundred operating conditions of experiment are selected as training models to train the network and 23 operating conditions are selected as test samples. Table 3 and Table 4 show the result of identification, in which the identification ability of the neural network is very good.

Table 4. Result of identification use Back Propagation Artificial Neural Networks

\begin{tabular}{lccc}
\hline & Stratified flow & Plug flow & Slug flow \\
\hline Number of flow pattern & 5 & 9 & 9 \\
Number of correct identification & 5 & 9 & 8 \\
Accuracy of identification rating & $100 \%$ & $100 \%$ & $98 \%$ \\
\hline
\end{tabular}

\section{Conclusion}

This paper uses a differential pressure transducer to measure the differential pressure of two phase flow and through neural network intelligently identifies the flow pattern. Statistical analysis of PSD was used to quantify the characteristics of the differential pressure signals at different flow conditions. Results showed that the method has the merits such as easy computation and easily quantifying the characteristics of the measured signals. This method has a advantage method for the industrial application such as high accuracy, fast and without artificial intervention.

\section{Nomenclature}

$\mathrm{ANN}=$ artificial neural network

$D P=$ differential pressure $(\mathrm{Pa})$

$\overline{D P}=$ average differential pressure $(\mathrm{Pa})$

$D P^{*}=$ normalized pressure different $\operatorname{signal}(\mathrm{Pa})$

$\mathrm{J}_{\mathrm{L}}=$ water superficial velocity $(\mathrm{m} / \mathrm{s})$

$\mathrm{J}_{\mathrm{G}}=$ air superficial velocity $(\mathrm{m} / \mathrm{s})$

PSD $=$ Power spectral density

\section{Acknowledgments}

This work was supported by DP2M DIKTI (Directorate of Research and Public Service of Directorate General of Higher Education) Ministry of Education and Culture Indonesia through the Competitive Grant Research and "Hibah Pascasarjana UGM 2012".

\section{Reference}

Cai, S., Haluk, T., Jianhung, Q., \& John, S. A. (1994). Neural Network Based Objective Flow Regime Identification in Air-Water Two Phase Flow. The Canadian Journal of Chemical Engineering, 72, 440-445. http://dx.doi.org/10.1002/cjce.5450720308

Demuth, H., \& Beale, M. (2000). Neural Network Toolbox for Use with MATLAB. The MathWorks, Inc. 
Drahos, J., Tihon, J., Serio, C., \& Liibbert, A. (1996). Deterministic chaos analysis of pressure fluctuations in a horizontal pipe at intermittent flow regime. The Chemical Engineering Journal, 64, 149-156. http://dx.doi.org/10.1016/S0923-0467(96)03128-4

Drahos, J., Zahradnik, J., Puncochar, M., Fialova, M., \& Bradka, F. (1991). Effect of operating conditions on the characteristics of pressure fluctuations in a bubble column. Chemical Engineering and Processing, 29, 107-115. http://dx.doi.org/10.1016/0255-2701(91)87019-Y

Ding, H., Zhiyao, H., Zhihuan, S., \& Yong, Y. (2007). Hilbert-Huang transform based signal analysis for the characterization of gas-liquid two-phase flow. Flow Measurement and Instrumentation, 18, 37-46. http://dx.doi.org/10.1016/j.flowmeasinst.2006.12.004

Fausett, L. (1994). Fundamental of Neural Networks. Prentice Hill, New Jersy .

Jia, Z., Niu, G., \& Wang, J. (2005). Identification of flow regimes in a horizontal flow using neural network. Journal of Hydrodynamics, Ser. B, 17(1), 66-73, China Ocean Press.

Matsui, G., Fujino, G., \& Suzuki, M. (2007). Two Phase Flow sensing using differential pressure fluctuations. Jurnal of JSEM, 7, 50-55.

Wu, H., Zhou, F., \& Wu, Y. (2001). Intelligent identification system of flow regime of oil-gas-water multiphase flow. International Journal of Multiphase Flow, 27(3), 459-475. http://dx.doi.org/10.1016/S0301-9322(00)00022-7

Xie, T., Ghiaasiaan, S. M., \& Karrila, S. (2004). Artificial neural network approach for flow regime classification in gas-liquid-fiber flows based on frequency domain analysis of pressure signals. Chemical Engineering Science, 59(11), 2241-2251. http://dx.doi.org/10.1016/j.ces.2004.02.017

\section{Appendix}

\section{The PSD Theory}

The goal of spectral analysis is to describe the distribution of the power contained in a signal over a frequency, based on a finite set of data. It converts information available in the time-domain into the frequency-domain. The averaged modified periodogram method was adopted to diminish the distortion of the spectrum due to a finite length of data record. If $x(n)(n=0,1, \ldots, N-1)$ is only measured over a finite interval, the power spectral density may be computed using the periodogram method:

$$
P x(f)=\sum_{k=-\infty}^{\infty} \hat{R} x(k) e^{i 2 \pi k f / f s}
$$

Where: $N$ is finite length of a discrete time signal, $k$ is discrete time shift, $\mathrm{f}$ is frequency, $f_{S}$ is the sampling frequency and the autocorrelation is given as

$$
\hat{R} x(k)=\frac{1}{N} \sum_{n=-N}^{N-1-k} x(n+k) x(n)
$$

\section{The Statistical Theory}

The statistical analysis methods mentioned clustered PSD data are mean and variance. These features are used as inputs to the neural network.

The mean is given by,

$$
\mu=\frac{1}{N} \sum_{i=1}^{N} x_{i}
$$

The variance is given as,

$$
\sigma=\frac{1}{(N-1)} \sum_{i=1}^{N}\left(x_{i}-\mu\right)^{2}
$$


These networks usually contain three types of layers:

1. An input layer

2. A hidden layer sigmoid bipolar and

3. An output layer linear transfer/ramp

Training process:

Step 1. Design the structure of neural network and input parameters of the network

Step 2. Get initial weights $\mathrm{W}$ and initial $\theta$ values from randomizing.

Step 3. Input training data matrix $\mathrm{X}$ and output matrix $\mathrm{T}$.

Step 4. Compute the output vector of each neural unit.

(a) Compute the output vector $\mathrm{H}$ of the hidden layer

$$
\begin{aligned}
\text { net }_{k} & =\sum W_{i k} X_{i}-\theta_{k} \\
H_{k} & =f\left(\text { net }_{k}\right)
\end{aligned}
$$

(b) Compute the output vector $\mathrm{Y}$ of the output layer

$$
\begin{aligned}
n e t_{j} & =\sum W_{k j} H_{i}-\theta_{j} \\
Y_{j} & =f\left(\text { net }_{j}\right)
\end{aligned}
$$

Step 5. Compute the distances $\delta$

(a) Compute the distances $d$ of the output layer

$$
\delta_{j}=\left(T_{j}-Y_{j}\right) \bullet f^{\prime}\left(\text { net }_{j}\right)
$$

(b) Compute the distances $\delta$ of the hidden layer

$$
\delta_{k}=\left(\sum_{j} \delta_{j} W_{k j} \bullet f^{\prime}\left(\text { net }_{k}\right)\right)
$$

Step 6. Compute the modification of $\mathrm{W}$ and $\theta$ ( $\eta$ is the learning rate)

(a) Compute the modification of $\mathrm{W}$ and $\theta$ of the output layer

$$
\begin{gathered}
\Delta W_{k j}=\eta \delta_{j} H_{k} \\
\Delta \theta_{j}=-\eta \delta_{j}
\end{gathered}
$$

(b) Compute the modification of $\mathrm{W}$ and $\theta$ of the hidden layer

$$
\begin{gathered}
\Delta W_{i k}=\eta \delta_{k} X_{i} \\
\Delta \theta_{k}=-\eta \delta_{k}
\end{gathered}
$$

Step 7. Renew $\mathrm{W}$ and $\theta$

(a) Renew $\mathrm{W}$ and $\theta$ of the output layer

$$
\begin{gathered}
W_{k j}=W_{k j}+\Delta W_{k j} \\
\theta_{j}=\theta_{j}+\Delta \theta_{j}
\end{gathered}
$$

(b) Renew $\mathrm{W}$ and $\theta$ of the hidden layer 


$$
\begin{gathered}
W_{i k}=W_{i k}+\Delta W_{i k} \\
\theta_{k}=\theta_{k}+\Delta \theta_{k}
\end{gathered}
$$

Step 8. Repeat step 3 to step7 until convergence.

Testing process:

Step 1. Input the parameters of the network.

Step 2. Input the $\mathrm{W}$ and $\theta$

Step 3. Input an unknown data matrix $X$

Step 4. Compute the output vector

(a) Compute the output vector $\mathrm{H}$ of hidden layer

$$
\begin{aligned}
& n e t_{k}=\sum W_{i k} X_{i}-\theta_{k} \\
& H_{k}=f\left(\text { net }_{k}\right)
\end{aligned}
$$

(b) Compute the output vector $\mathrm{Y}$ of the output layer

$$
\begin{aligned}
n e t_{j} & =\sum W_{k j} H_{i}-\theta_{j} \\
Y_{j} & =f\left(\text { net }_{j}\right)
\end{aligned}
$$

